\title{
Oxidative Amination of the Zinc Bromide Complex of $\beta$-Enamino Esters
}

Key words

amination

zinc

pyrroles

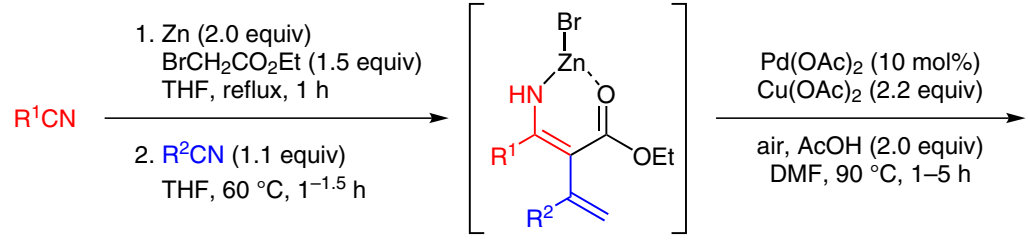

$\mathrm{R}^{1}=\mathrm{Alk}, \mathrm{Ar}, \mathrm{HetAr}, \mathrm{Bn}$

$\mathrm{R}^{2}=\mathrm{Alk}, \mathrm{Ar}, \mathrm{CH}_{2} \mathrm{CH}_{2} \mathrm{Ph}$

Selected examples:

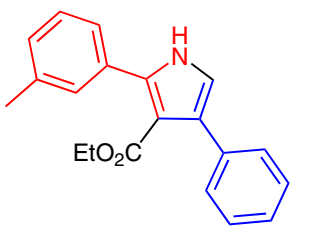

$82 \%$ yield

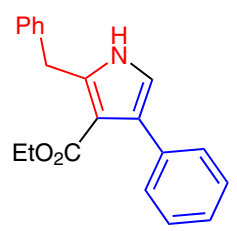

$79 \%$ yield

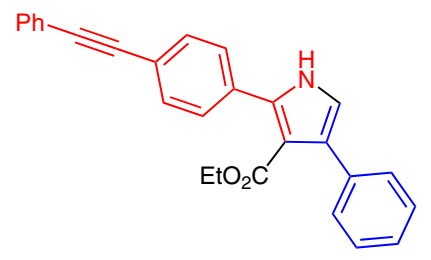

$65 \%$ yield

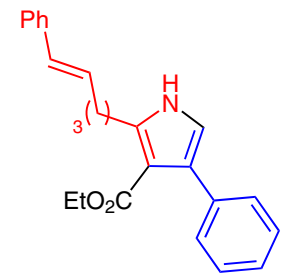

$77 \%$ yield

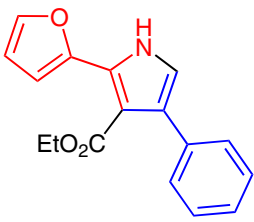

$70 \%$ yield

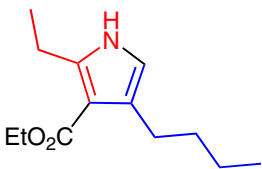

$64 \%$ yield

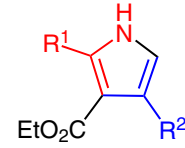

$61-88 \%$ yield
Significance: Lee and co-workers report a tandem palladium-catalyzed intramolecular oxidative olefin amination of the zinc bromide complex of $\alpha$-vinylated $\beta$-amino esters to afford various $2,3,4$ trisubstituted pyrroles in good yields.
Comment: The synthetic utility of this efficient and atom-economical procedure is shown by the synthesis of pyrrolophenanthrenes and pyranopyrrolones through selective palladium- and coppercatalyzed $\mathrm{C}-\mathrm{C}$ and $\mathrm{C}-\mathrm{O}$ bond-forming reactions.

SYNFACTS Contributors: Paul Knochel, Diana Haas 